\title{
$\beta$-glucan reduces exercise-induced stress through downregulation of c-Fos and c-Jun expression in the brains of exhausted rats
}

\author{
HEEOK HONG ${ }^{1}$, CHANG-JU KIM ${ }^{2}$, JAE-DEUNG KIM ${ }^{3}$ and JIN-HEE SEO ${ }^{4}$ \\ ${ }^{1}$ Department of Medical Science, School of Medicine, Konkuk University, Seoul 143-701; ${ }^{2}$ Department of Physiology, \\ College of Medicine, Kyung Hee University, Seoul 130-701; ${ }^{3}$ Department of Physical Education, Korea University, \\ Seoul 136-701; ${ }^{4}$ Division of Sports Science, Baekseok University, Cheonan 330-704, Republic of Korea
}

Received August 28, 2013; Accepted February 19, 2014

DOI: $10.3892 / \mathrm{mmr} .2014 .2005$

\begin{abstract}
Immediate-early genes are involved in acute stress responses in the central nervous system. $\beta$-glucan stimulates innate immune defenses, exerts an anti-tumor response and increases resistance to a wide variety of types of infection. To date, the effect of $\beta$-glucan on the expression of immediate-early genes under stressful conditions has not been elucidated. In the present study, the effects of $\beta$-glucan on the expression of the oncogenes c-Fos and c-Jun in the hypothalamus, dentate gyrus and dorsal raphe in rats following exhaustive treadmill running were investigated. Male Sprague Dawley rats were randomly divided into five groups ( $\mathrm{n}=10$ in each group) as follows: Control, exercise, exercise and $50 \mathrm{mg} / \mathrm{kg} \beta$-glucan treatment, exercise and $100 \mathrm{mg} / \mathrm{kg} \beta$-glucan treatment, and exercise and $200 \mathrm{mg} / \mathrm{kg} \beta$-glucan treatment. Rats in the $\beta$-glucan-treated groups were administered $\beta$-glucan at the respective dose once per day for seven days. Rats in the exercise groups performed treadmill running once per day for six days. On the seventh day of the experiment, the time to exhaustion in response to treadmill running was determined for the exercise groups. The expression of c-Fos and c-Jun in the hypothalamus, dorsal raphe and hippocampus was enhanced by exhaustive treadmill running. Administration of $\beta$-glucan resulted in an increase in the time to exhaustion and the suppression of the exercise-induced increment in c-Fos and c-Jun expression. In conclusion, $\beta$-glucan may exert an alleviating effect on exercise-induced stress through the suppression of c-Fos and c-Jun expression in the brains of exhausted rats.
\end{abstract}

\section{Introduction}

Immediate-early genes are involved in acute stress responses in the central nervous system (1). Stress results in the high

Correspondence to: Professor Jin-Hee Seo, Division of Sports Science, Baekseok University, 115 Anseo-dong, Cheonan 330-704, Republic of Korea

E-mail: sjh0521@bu.ac.kr

Key words: $\beta$-glucan, c-Fos, c-Jun, exhaustive exercise, stress expression of immediate-early genes, including c-Fos, c-Jun, JunB and JunD, in the hypothalamic paraventricular nucleus and the central amygdaloid nucleus, suggesting that stress may affect neurotransmitter gene expression through Fos and Jun proteins in these nuclei (2). Stress affects the hypothalamic-pituitary-adrenal axis, resulting in constant secretion of corticosterone from the adrenal gland (3). Immediate-early genes have been considered to be reliable markers for the identification of activated cells under stressful conditions $(4,5)$. Running at moderate or high intensity leads to a significant elevation in the number of c-Fos-positive cells in the paraventricular nucleus (6). c-Fos and c-Jun are known to participate in cell growth, mitosis $(7,8)$, differentiation, development $(9,10)$ and the regulation of the expression of other genes $(11,12)$. Immediate-early genes have an important role in the regulation of the nervous system in response to stress, and the expression of these genes is used as a marker for neuronal activity in the brain following exposure to stressful stimuli $(13,14)$.

Exercise can be employed as a model of the temporary immunosuppression that occurs following severe physical stress, resulting in deterioration of the immune system and leading to infection or cancer $(15,16)$. Prolonged exhaustive exercise leads to central fatigue and this type of fatigue limits endurance exercise performance through limitation of brain function $(17,18)$. As a result, exhaustive treadmill running has been used as an animal model of stressful conditions, and alleviation of brain stress has been shown to result in an increase in the time to exhaustion in response to treadmill running $(19,20)$.

$\beta$-glucan is the major structural component of the cell wall in yeast and fungi, including mushrooms. $\beta$-glucan prevents oxidative injury, stimulates innate immune defenses, exerts anti-tumor responses and increases resistance to a wide variety of infections (21-23). $\beta$-glucan also exhibits hypocholesterolemic and anti-coagulant properties, making it a promising candidate for a pharmacological promoter of health (21). Orally administered water-soluble glucan is translocated from the gastrointestinal tract into the systemic circulation and induces protection against infection (22).

Numerous pharmacological effects of $\beta$-glucan have been reported; however, the effects of $\beta$-glucan on the expression of immediate-early genes under stressful conditions have yet to be elucidated. In the present study, the effects of $\beta$-glucan on the expression of c-Fos and c-Jun in the hypothalamus, dentate 
gyrus and dorsal raphe following exhaustive treadmill running were assessed.

\section{Materials and methods}

Animals. Adult male Sprague Dawley rats, weighing $203.7 \pm 12.8 \mathrm{~g}$ (seven weeks old) were obtained from a commercial breeder (Dae Han Bio Link Co., Chungbuk, Korea). The animals were housed at a controlled temperature $\left(20 \pm 2^{\circ} \mathrm{C}\right)$ with a 12-h light/dark cycle (light from 7.00 a.m. to 7.00 p.m.). Food and water were available ad libitum. All experimental procedures were performed in accordance with the Animal Care Guidelines of the National Institutes of Health and the Korean Academy of Medical Sciences (Seoul, Korea).

Animals were randomly divided into five groups: Control, exercise, exercise and $50 \mathrm{mg} / \mathrm{kg} \beta$-glucan treatment, exercise and $100 \mathrm{mg} / \mathrm{kg} \beta$-glucan treatment, and exercise and $200 \mathrm{mg} / \mathrm{kg}$ $\beta$-glucan treatment ( $\mathrm{n}=10$ in each group). The water-soluble glucan (Tokyo Chemical Industry Co., Ltd., Tokyo, Japan) used in this study was $\beta$-1,3-glucan in microparticulate form. The $\beta$-glucan solution was diluted with drinking water to concentrations of 50,100 and $200 \mathrm{mg} / \mathrm{kg}$ and was made fresh daily. Rats in the $\beta$-glucan treatment groups were administered $\beta$-glucan at three different doses $(50,100$ and $200 \mathrm{mg} / \mathrm{kg}$ of body weight, respectively) per day for seven days. The treatment was administered $60 \mathrm{~min}$ prior to the start of exercise, which was conducted as described below. Rats in the control and exercise groups received water by oral gavage once per day for seven days.

Exercise protocols. The physical exercise load applied in the present study consisted of running on a motor-driven treadmill without inclination. Rats in the exercise groups were forced to run on a treadmill for 30 min once per day during a period of six consecutive days, whereas rats in the control group were left on the treadmill without running for $30 \mathrm{~min}$. The exercise load consisted of forced running at a speed of $10 \mathrm{~m} / \mathrm{min}$ for $10 \mathrm{~min}$, followed by $16 \mathrm{~m} / \mathrm{min}$ for $10 \mathrm{~min}$ and then $21 \mathrm{~m} / \mathrm{min}$ for a final $10 \mathrm{~min}$.

On the seventh day of the experiment, the time to exhaustion during treadmill running was determined for the exercise groups. The time to exhaustion was defined as the time between the commencement of exercise and the first occurrence of a failure to keep up with the treadmill for a period of $\geq 3 \mathrm{~min}$. The speeds used for the determination of the time to exhaustion were $10 \mathrm{~m} / \mathrm{min}$ for $5 \mathrm{~min}$, followed by $16,18,21,24,26$, $29,32,34$ and $37 \mathrm{~m} / \mathrm{min}$ for $3 \mathrm{~min}$ each and then $40 \mathrm{~m} / \mathrm{min}$ until exhaustion, as described in a previous study (19).

Brain preparation. The animals were sacrificed on the seventh day of the experiments immediately following determination of the exhaustion time. For preparation of the brains, the animals were fully anesthetized with Zoletil $50^{\circledR}(10 \mathrm{mg} / \mathrm{kg}$, intraperitoneal; Vibac, Carros, France). The rats then received a transcardial perfusion with $50 \mathrm{mM}$ phosphate-buffered saline (PBS) and were fixed with a freshly prepared solution of $4 \%$ paraformaldehyde in $100 \mathrm{mM}$ phosphate buffer ( $\mathrm{pH}$ 7.4). The brains were then removed, post-fixed in the same fixative overnight and transferred to a $30 \%$ sucrose solution for cryoprotection. Coronal sections with a thickness of $40 \mu \mathrm{m}$ were prepared using a frozen microtome (Leica, Nussloch, Germany).

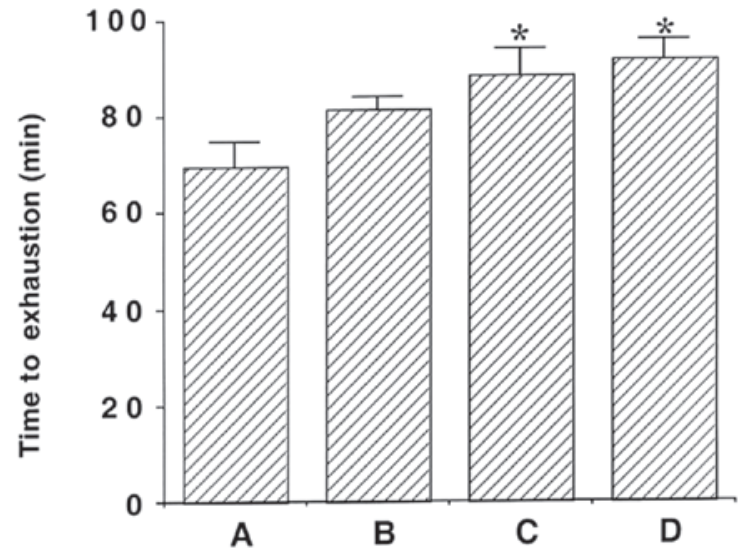

Figure 1. Treadmill running time to exhaustion in response to treatment with $\beta$-glucan. (A) Exercise; (B) exercise and $50 \mathrm{mg} / \mathrm{kg} \beta$-glucan treatment; (C) exercise and $100 \mathrm{mg} / \mathrm{kg} \beta$-glucan treatment and (D) exercise and $200 \mathrm{mg} / \mathrm{kg} \beta$-glucan treatment. Values are expressed as the mean \pm standard error of the mean. ${ }^{*} \mathrm{P}<0.05$ as compared with the exercise group.

Immunohistochemical detection of c-Jun and c-Fos. Immunohistochemistry was performed for evaluation of c-Fos- and c-Jun-positive cells in the dorsal raphe (bregma, from -7.08 to $-7.56 \mathrm{~mm}$ ), the hypothalamus (bregma, from -1.80 to $-1.92 \mathrm{~mm}$ ) and the hippocampus (bregma, from -2.92 to $-3.24 \mathrm{~mm}$ ), according to the previously described method $(14,24)$. The sections were incubated in PBS for $10 \mathrm{~min}$ and then washed three times in the same buffer. The sections were subsequently incubated in $1 \%$ hydrogen peroxide $\left(\mathrm{H}_{2} \mathrm{O}_{2}\right)$ for $30 \mathrm{~min}$, prior to being incubated overnight with rabbit anti-c-Fos antibody (1:1,000; Santa Cruz Biotechnology, Inc., Santa Cruz, CA, USA) and rabbit anti-c-Jun antibody (1:1,000; Santa Cruz Biotechnology, Inc.). The sections were then incubated for $1 \mathrm{~h}$ with biotinylated anti-rabbit secondary antibody (1:200; Vector Laboratories, Inc., Burlingame, CA, USA) for c-Fos and c-Jun immunohistochemistry. The sections were subsequently incubated with avidin-biotin-peroxidase complex (1:100; Vector Laboratories, Inc.) for $1 \mathrm{~h}$ at room temperature. For staining, the sections were incubated in a solution consisting of $0.05 \% 3,3$ '-diaminobenzidine tetrahydrochloride and $0.03 \% \mathrm{H}_{2} \mathrm{O}_{2}$ in $50 \mathrm{mM}$ Tris- $\mathrm{HCl}$ ( $\mathrm{pH} 7.6$ ) for $\sim 5 \mathrm{~min}$, washed with PBS and mounted onto gelatin-coated slides. The slides were air-dried overnight at room temperature and coverslips were mounted using Permount mounting medium (Thermo Fisher Scientific, Inc., Waltham, MA, USA). The numbers of c-Fos- and c-Jun-positive cells in the dorsal raphe, the hypothalamus and hippocampus were counted hemilaterally using a microscope (Olympus, Tokyo, Japan).

Statistical analysis. Values are expressed as the mean \pm standard error of the mean. Data were analyzed by one-way analysis of variance, followed by Duncan's post hoc test using SPSS software (SPSS, Inc., Chicago, IL, USA). $\mathrm{P}<0.05$ was considered to indicate a statistically significant difference.

\section{Results}

Effect of $\beta$-glucan on time to exhaustion during treadmill running. The effects of $\beta$-glucan on time to exhaustion are shown in Fig. 1. The average running time until fatigue 


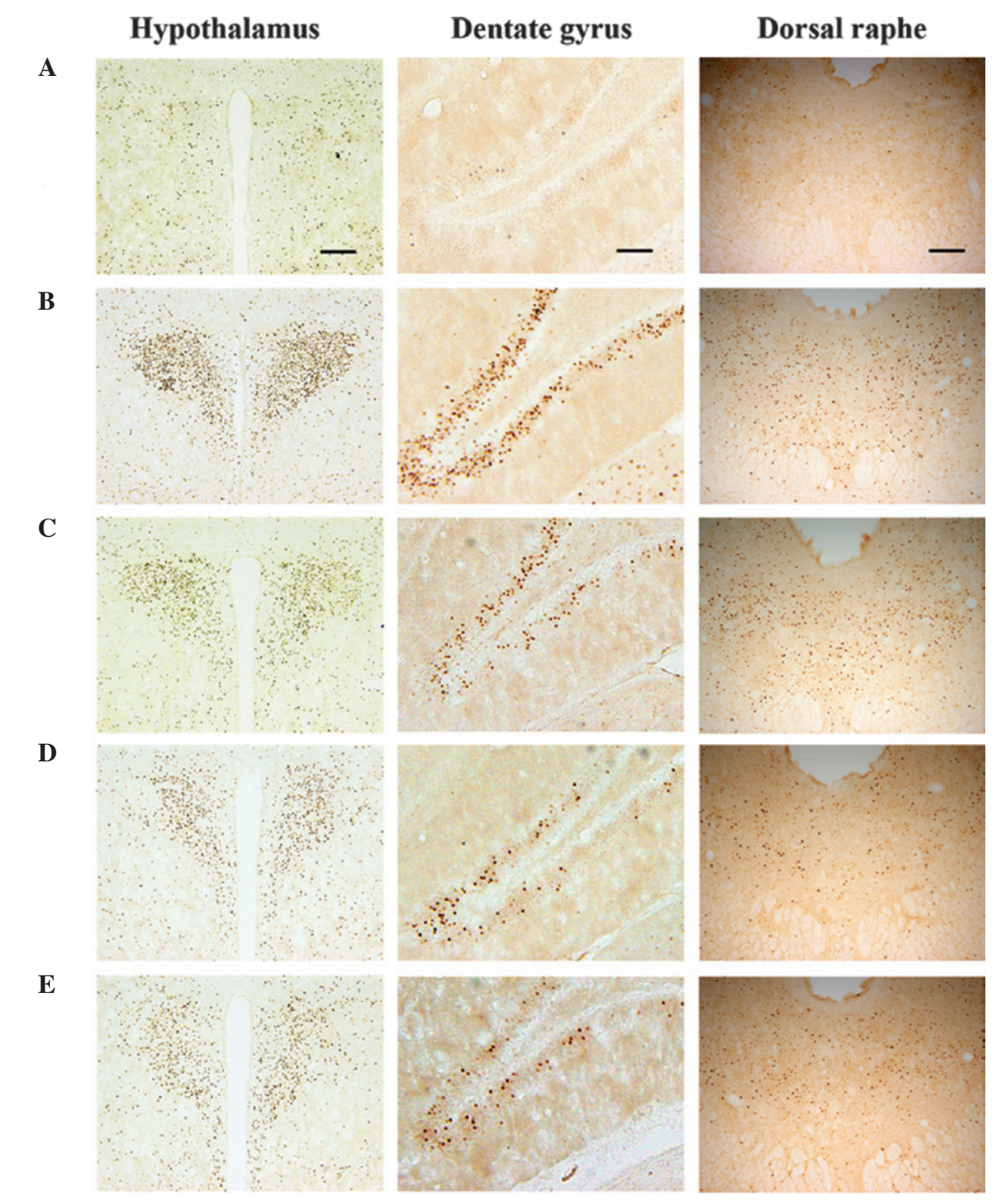

Figure 2. c-Fos immunohistochemistry in the hypothalamus, dentate gyrus and dorsal raphe nucleus. The scale bar represents $250 \mu \mathrm{m}$ (x4) for the hypothalamus and dorsal raphe and $50 \mu \mathrm{m}$ (x20) for the dentate gyrus. (A) Control; (B) exercise; (C) exercise and $50 \mathrm{mg} / \mathrm{kg} \beta$-glucan treatment; (D) exercise and $100 \mathrm{mg} / \mathrm{kg} \beta$-glucan treatment and (E) exercise and $200 \mathrm{mg} / \mathrm{kg} \beta$-glucan treatment.

was $69.88 \pm 5.16 \mathrm{~min}$ in the exercise, $81.66 \pm 2.34 \mathrm{~min}$ in the $50 \mathrm{mg} / \mathrm{kg} \beta$-glucan-treated, $88.66 \pm 5.42 \mathrm{~min}$ in the $100 \mathrm{mg} / \mathrm{kg} \beta$-glucan-treated and $91.77 \pm 4.04 \mathrm{~min}$ in the $200 \mathrm{mg} / \mathrm{kg} \beta$-glucan-treated groups. These findings indicate that the time to exhaustion in response to treadmill running increased following treatment with $\beta$-glucan $(\mathrm{P}<0.05)$. In particular, treatment with 100 and $200 \mathrm{mg} / \mathrm{kg} \beta$-glucan resulted in a significant increase in the time to exhaustion by treadmill running as compared with the exercise group $(\mathrm{P}<0.05)$.

Effect of $\beta$-glucan on the expression of c-Fos in the hypothalamus, dentate gyrus and dorsal raphe. Photomicrographs of c-Fos-positive cells in the hypothalamus, dentate gyrus and dorsal raphe are shown in Fig. 2. The number of c-Fos-positive cells in the hypothalamus was $19.28 \pm 1.78$ in the control, $190.71 \pm 30.56$ in the exercise, $175.42 \pm 19.98$ in the $50 \mathrm{mg} / \mathrm{kg} \beta$-glucan-treated, $98.14 \pm 18.54$ in the $100 \mathrm{mg} / \mathrm{kg} \beta$-glucan-treated and $133.57 \pm 10.35$ in the $200 \mathrm{mg} / \mathrm{kg} \beta$-glucan-treated groups. These results demonstrate that treadmill exercise led to increased expression of c-Fos in the hypothalamus $(\mathrm{P}<0.05)$ and that treatment with $\beta$-glucan resulted in the suppression of the exercise-induced expression of $\mathrm{c}-\mathrm{Fos}(\mathrm{P}<0.05)$. In particular, treatment with $\beta$-glucan at $100 \mathrm{mg} / \mathrm{kg}$ resulted in the statistically significant suppression of c-Fos expression in the hypothalamus as compared with the exercise group $(\mathrm{P}<0.05)$ (Fig. 3).

The number of c-Fos-positive cells in the dentate gyrus was $57.50 \pm 3.43$ in the control, $1,218.66 \pm 65.97$ in the exercise, $888.66 \pm 56.14$ in the $50 \mathrm{mg} / \mathrm{kg} \beta$-glucan-treated, $614.66 \pm 37.38$ in the $100 \mathrm{mg} / \mathrm{kg} \beta$-glucan-treated and $688.83 \pm 73.88$ in the $200 \mathrm{mg} / \mathrm{kg} \beta$-glucan-treated groups. These results demonstrate that treadmill exercise led to increased expression of c-Fos in the dentate gyrus $(\mathrm{P}<0.05)$ and that treatment with $\beta$-glucan 

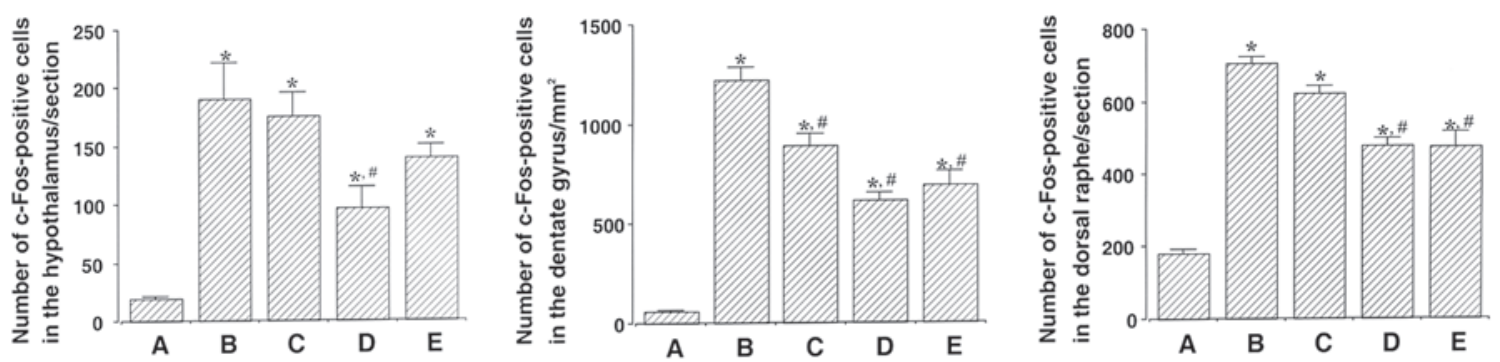

Figure 3. Number of c-Fos-positive cells in the hypothalamus, dentate gyrus and dorsal raphe nucleus in each group. (A) Control; (B) exercise; (C) exercise and $50 \mathrm{mg} / \mathrm{kg} \beta$-glucan treatment; (D) exercise and $100 \mathrm{mg} / \mathrm{kg} \beta$-glucan treatment and (E) exercise and $200 \mathrm{mg} / \mathrm{kg} \beta$-glucan treatment. Values are expressed as the mean \pm standard error of the mean. ${ }^{*} \mathrm{P}<0.05$ as compared with the control group; ${ }^{*} \mathrm{P}<0.05$ as compared with the exercise group.

resulted in the suppression of the exercise-induced expression of $\mathrm{c}$-Fos $(\mathrm{P}<0.05)$. In particular, treatment with $\beta$-glucan at 100 and $200 \mathrm{mg} / \mathrm{kg}$ resulted in the statistically significant suppression of c-Fos expression in the dentate gyrus as compared with the exercise group $(\mathrm{P}<0.05)$ (Fig. 3).

The number of c-Fos-positive cells in the dorsal raphe was $180.42 \pm 13.19$ in the control, $705.00 \pm 19.11$ in the exercise, $623.00 \pm 19.71$ in the $50 \mathrm{mg} / \mathrm{kg} \beta$-glucan-treated, $476.57 \pm 20.41$ in the $100 \mathrm{mg} / \mathrm{kg} \beta$-glucan-treated and $475.00 \pm 40.13$ in the $200 \mathrm{mg} / \mathrm{kg} \beta$-glucan-treated groups. These results demonstrate that treadmill exercise led to increased expression of c-Fos in the dorsal raphe $(\mathrm{P}<0.05)$ and that treatment with $\beta$-glucan resulted in the suppression of the exercise-induced expression of c-Fos $(\mathrm{P}<0.05)$. In particular, treatment with $\beta$-glucan at 100 and $200 \mathrm{mg} / \mathrm{kg}$ resulted in the statistically significant suppression of c-Fos expression in the dorsal raphe as compared with the exercise group $(\mathrm{P}<0.05)$ (Fig. 3).

Effect of $\beta$-glucan on expression of $c$-Jun in the hypothalamus, dentate gyrus and dorsal raphe. Photomicrographs of c-Jun-positive cells in the hypothalamus, dentate gyrus and dorsal raphe are shown in Fig. 4. The number of c-Jun-positive cells in the hypothalamus was $26.88 \pm 2.45$ in the control, $130.88 \pm 17.85$ in the exercise, $117.22 \pm 13.73$ in the $50 \mathrm{mg} / \mathrm{kg} \beta$-glucan-treated, $70.55 \pm 10.34$ in the $100 \mathrm{mg} / \mathrm{kg} \beta$-glucan-treated and $97.22 \pm 5.65$ in the $200 \mathrm{mg} / \mathrm{kg}$ $\beta$-glucan-treated groups. These results demonstrate that treadmill exercise led to increased expression of c-Jun in the hypothalamus $(\mathrm{P}<0.05)$ and that treatment with $\beta$-glucan resulted in the suppression of the exercise-induced expression of c-Jun $(\mathrm{P}<0.05)$. In particular, treatment with $\beta$-glucan at $100 \mathrm{mg} / \mathrm{kg}$ resulted in the statistically significant suppression of c-Jun expression in the hypothalamus as compared with the exercise group $(\mathrm{P}<0.05)$ (Fig. 5).

The number of c-Jun-positive cells in the dentate gyrus was $88.00 \pm 2.20$ in the control, $122.40 \pm 4.61$ in the exercise, $103.05 \pm 0.65$ in the $50 \mathrm{mg} / \mathrm{kg} \beta$-glucan-treated, $97.83 \pm 1.02$ in the $100 \mathrm{mg} / \mathrm{kg} \beta$-glucan-treated and $99.59 \pm 1.08$ in the $200 \mathrm{mg} / \mathrm{kg} \beta$-glucan-treated groups. These results demonstrate that treadmill exercise led to increased expression of c-Jun in the dentate gyrus $(\mathrm{P}<0.05)$ and that treatment with $\beta$-glucan resulted in the suppression of the exercise-induced expression of c-Jun $(\mathrm{P}<0.05)$. In particular, treatment with $\beta$-glucan resulted in the statistically significant suppression of c-Jun expression in the dentate gyrus as compared with the exercise group $(\mathrm{P}<0.05)$ (Fig. 5).
The number of c-Jun-positive cells in the dorsal raphe was $401.33 \pm 43.19$ in the control, $763.50 \pm 51.96$ in the exercise, $511.50 \pm 31.78$ in the $50 \mathrm{mg} / \mathrm{kg} \beta$-glucan-treated, $468.16 \pm 43.82$ in the $100 \mathrm{mg} / \mathrm{kg} \beta$-glucan-treated and $472.16 \pm 13.77$ in the $200 \mathrm{mg} / \mathrm{kg} \beta$-glucan-treated groups. These results demonstrate that treadmill exercise led to increased expression of c-Jun in the dorsal raphe $(\mathrm{P}<0.05)$ and that treatment with $\beta$-glucan resulted in the suppression of the exercise-induced expression of c-Jun $(\mathrm{P}<0.05)$. In particular, treatment with $\beta$-glucan resulted in statistically significant suppression of c-Jun expression in the dorsal raphe as compared with the exercise group $(\mathrm{P}<0.05)$ (Fig. 5).

\section{Discussion}

Previous studies have used the expression of c-Fos and c-Jun as a marker for stimuli-induced changes in the metabolic activity of neurons under various conditions $(1,2,25,26)$. The application of stressful stimuli resulted in the enhanced expression of c-Fos and c-Jun $(6,14,24,27)$. The expression of four immediate-early genes (c-Fos, c-Jun, JunB and NGFI-B) was increased following $30 \mathrm{~min}$ of global ischemia (24). Rats receiving predator stress during pregnancy exhibited anxiety-like behavior with higher expression of c-Fos in the hypothalamus and locus coeruleus following delivery (14). Running at a moderate speed $(25 \mathrm{~m} / \mathrm{min})$ led to increased induction of c-Fos in various hypothalamic regions; however, running at a low speed $(15 \mathrm{~m} / \mathrm{min})$ had no effect on the expression of c-Fos (6). Expression of c-Fos in the brain areas associated with micturition was enhanced by the induction of stress urinary incontinence and the suppression of c-Fos expression led to amelioration of the symptoms of stress urinary incontinence (27). These results suggest that neuronal activation in the micturition centers was induced by stress urinary incontinence. The performance of acute exercise led to upregulated expression of c-Fos and c-Jun through activation of the mitogen-activated protein kinase signaling pathway (28). According to the present study, expression of c-Fos and c-Jun in the hypothalamus, dentate gyrus and dorsal raphe was enhanced by exhaustive treadmill running (Figs. 3 and 5), indicating that strenuous exercise acted as a form of physical stress and resulted in the enhancement of c-Fos and c-Jun expression in the brain.

Pharmacological agents acting as ergogenic aids through a reduction in fatigue have been widely investigated (17-19). Caffeine and Paeonia radix exhibited ergogenic effects during 
Hypothalamus

A

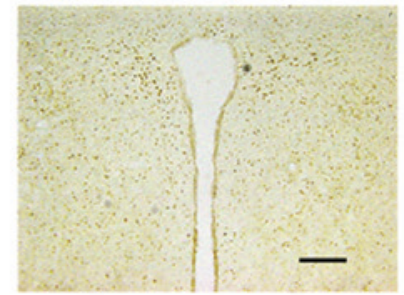

B

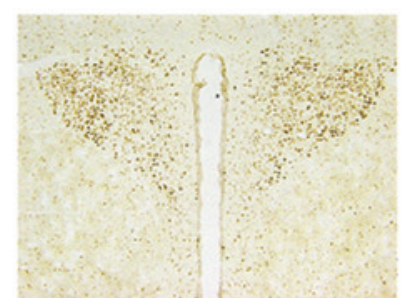

C

D
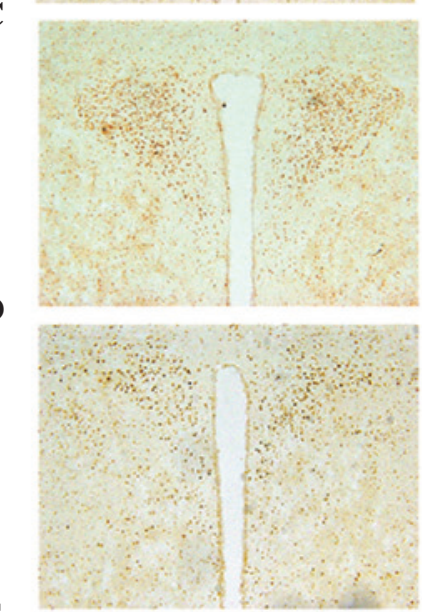

$\mathbf{E}$

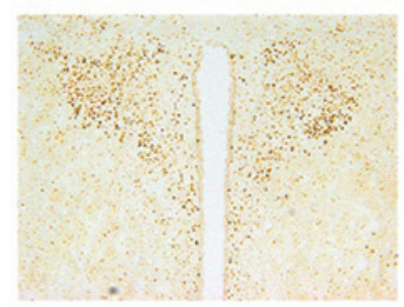

Dentate gyrus
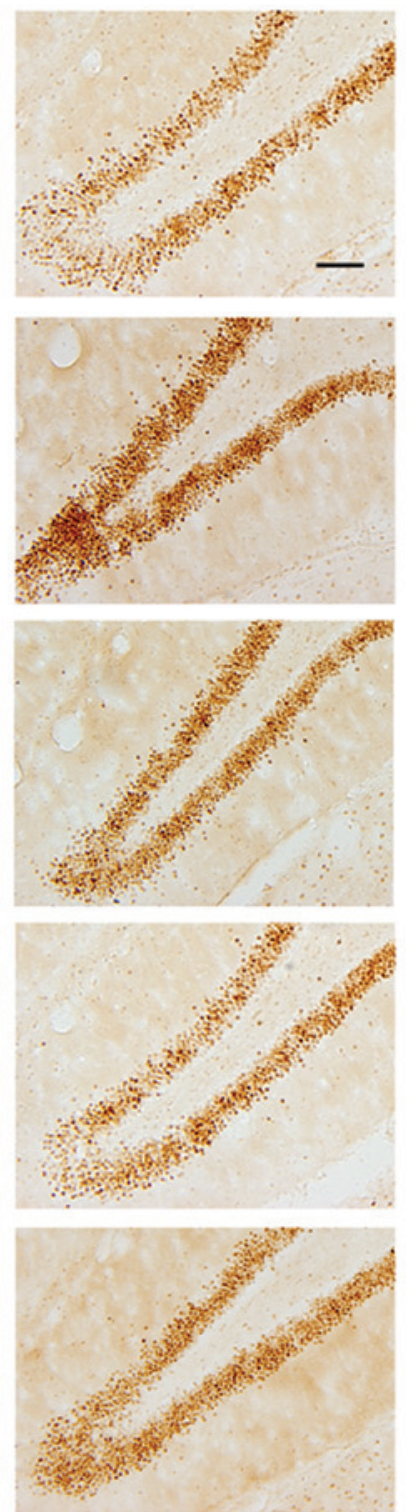

Dorsal raphe
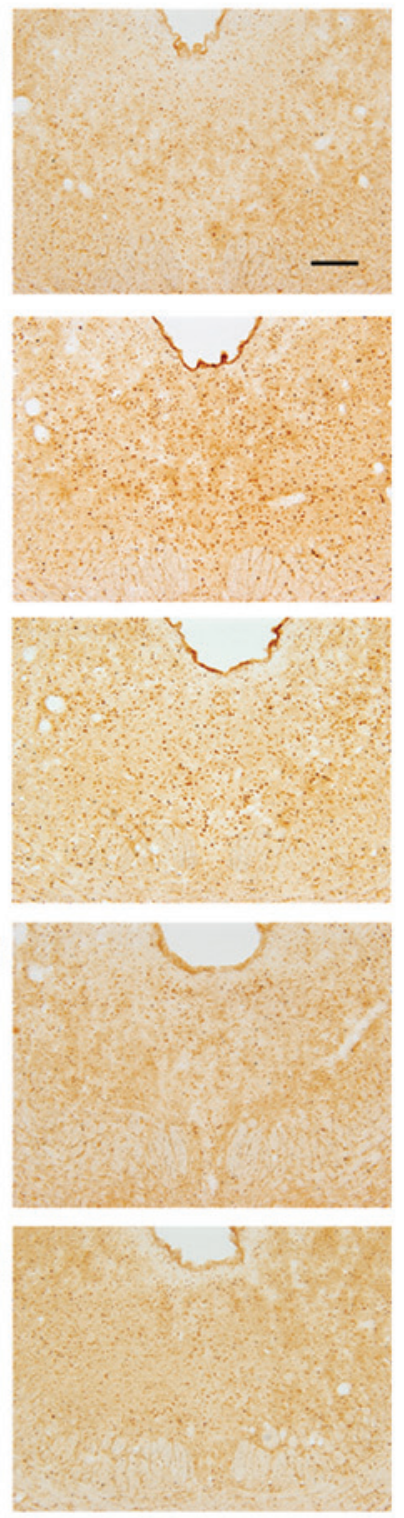

Figure 4. c-Jun immunohistochemistry in the hypothalamus, dentate gyrus and dorsal raphe nucleus. The scale bar represents $250 \mu \mathrm{m}$ (x4) for the hypothalamus and dorsal raphe and $50 \mu \mathrm{m}$ (x20) for the dentate gyrus. (A) Control; (B) exercise; (C) exercise and $50 \mathrm{mg} / \mathrm{kg} \beta$-glucan treatment; (D) exercise and $100 \mathrm{mg} / \mathrm{kg} \beta$-glucan treatment and (E) exercise and $200 \mathrm{mg} / \mathrm{kg} \beta$-glucan treatment.
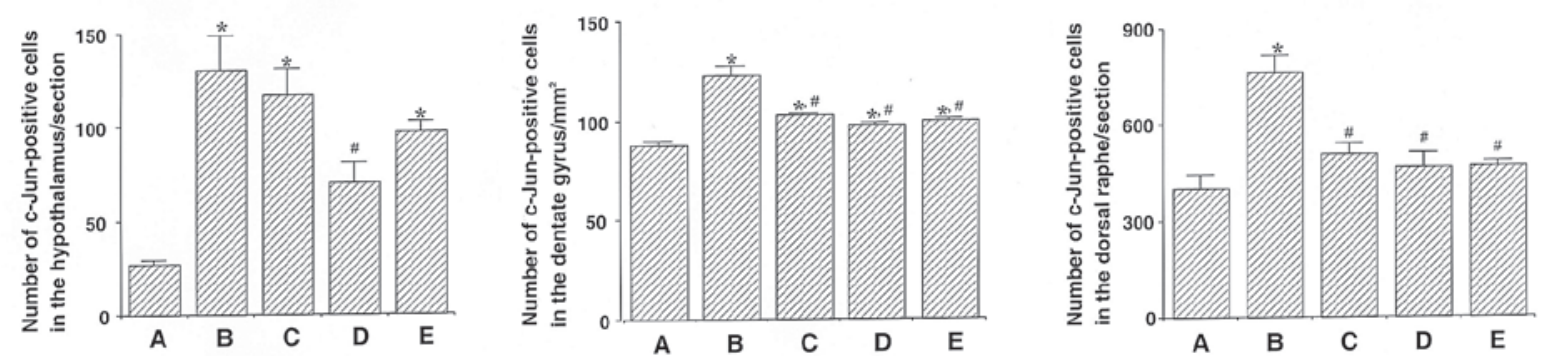

Figure 5. Number of c-Jun-positive cells in the hypothalamus, dentate gyrus and dorsal raphe nucleus in each group. (A) Control; (B) exercise; (C) exercise and $50 \mathrm{mg} / \mathrm{kg} \beta$-glucan treatment; (D) exercise and $100 \mathrm{mg} / \mathrm{kg} \beta$-glucan treatment and (E) exercise and $200 \mathrm{mg} / \mathrm{kg} \beta$-glucan treatment. Values are expressed as the mean \pm standard error of the mean. ${ }^{*} \mathrm{P}<0.05$ as compared with the control group; ${ }^{"} \mathrm{P}<0.05$ as compared with the exercise group.

exhaustive treadmill running $(17,18)$. Seo et al (19) reported that Phellinus linteus enhanced the time to exhaustion in response to treadmill running. Phellinus linteus has been used for the treatment of gastroenteric disorders, inflammation and lymphatic diseases (29-31). $\beta$-glucan also originates from Phellinus linteus, and the immunological response 
to $\beta$-glucans isolated from medicinal mushrooms has been well documented (32). Prolonged and high-intensity exercise in endurance athletes leads to a deterioration in immune function and increased risk of upper respiratory tract infections. The positive immunomodulatory effect of $\beta$-glucan on immunocompetent cells has been reported (33). Treatment with $\beta$-glucan increased production of interleukin-2, -4 and -5 and interferon- $\gamma$ in blood leucocytes, suggesting that $\beta$-glucan may alter immune function following strenuous exercise (34). $\beta$-glucan from dietary oats reduced the body weight and increased the maximum running time compared with that in control rats (35). In addition, $\beta$-glucan from dietary oats decreased the levels of blood urea nitrogen, lactic acid and creatine kinase activity in the serum and increased the levels of non-esterified fatty acids and lactic dehydrogenase activity in the serum as well as the content of liver glycogen. These results suggest that $\beta$-glucan from dietary oats can enhance the endurance capacity through the facilitation of recovery from fatigue (35). In the present study, treatment with $\beta$-glucan resulted in enhanced time to exhaustion in treadmill running (Fig. 1). Treatment with $\beta$-glucan also led to the alleviation of the exercise-induced increase in c-Fos and c-Jun expression in the hypothalamus, dentate gyrus and dorsal raphe (Figs. 3 and 5). These results suggest that $\beta$-glucan acted as an ergogenic aid during strenuous exercise through the suppression of stress-related neuronal parameters, including c-Fos and c-Jun, in the brain.

In conclusion, exposure to stressful stimuli, such as strenuous exercise, results in the enhanced expression of c-Fos and c-Jun in the brain. $\beta$-glucan reduces exercise-induced stress through downregulation of c-Fos and c-Jun following exhaustive exercise.

\section{Acknowledgements}

The present study was supported by the National Research Foundation of Korea Grant funded by the Korean Government (no. NRF-2009-351-G00080).

\section{References}

1. Schreiber SS, Tocco G, Shors TJ and Thompson RF: Activation of immediate early genes after acute stress. Neuroreport 2: 17-20, 1991.

2. Honkaniemi J, Kainu T, Ceccatelli S, Rechardt L, Hökfelt T and Pelto-Huikko M: Fos and jun in rat central amygdaloid nucleus and paraventricular nucleus after stress. Neuroreport 3: 849-852, 1992.

3. Zamora-González EO, Santerre A, Palomera-Avalos V and Morales-Villagrán A: A chronic combinatory stress model that activates the HPA axis and avoids habituation in BALB/C mice. J Neurosci Methods 213: 70-75, 2013.

4. Imaki T, Shibasaki T, Chikada N, Harada S, Naruse M and Demura H: Different expression of immediate-early genes in the rat paraventricular nucleus induced by stress: relation to corticotropin-releasing factor gene transcription: Endocr $\mathbf{J} 43$ : 629-638, 1996

5. Singewald N, Salchner P and Sharp T: Induction of c-Fos expression in specific areas of the fear circuitry in rat forebrain by anxiogenic drugs. Biol Psychiatry 53: 275-283, 2003.

6. Soya H, Mukai A, Deocaris CC, Ohiwa N, Chang H, Nishijima T, Fujikawa T, Togashi K and Saito T: Threshold-like pattern of neuronal activation in the hypothalamus during treadmill running: establishment of a minimum running stress (MRS) rat model. Neurosci Res 58: 341-348, 2007.

7. Kovary K and Bravo R: Expression of different Jun and Fos proteins during the G0-to-G1 transition in mouse fibroblasts: in vitro and in vivo associations. Mol Cell Biol 11: 2451-2459, 1991.
8. Kovary $\mathrm{K}$ and Bravo R: The jun and fos protein families are both required for cell cycle progression in fibroblasts. Mol Cell Biol 11: 4466-4472, 1991.

9. Caubet JF: c-fos proto-oncogene expression in the nervous system during mouse development. Mol Cell Biol 9: 2269-2272, 1989.

10. Wilkinson DG, Bhatt S, Ryseck RP and Bravo R: Tissue-specific expression of c-jun and junB during organogenesis in the mouse. Development 106: 465-471, 1989.

11. Akins PT, Liu PK and Hsu CY: Immediate early gene expression in response to cerebral ischemia. Friend or foe? Stroke 27: 1682-1687, 1996.

12. Sheng $M$ and Greenberg ME: The regulation and function of c-fos and other immediate early genes in the nervous system. Neuron 4: 477-485, 1990.

13. Jung JA, Yoo KS and Hwang KK: Changes of c-Fos immunoreactivity in midbrain by deep pain and effects of aspirin. Korean $\mathrm{J}$ Pediatr 46: 695-701, 2003.

14. Seo JH, Kim TW, Kim CJ, Sung YH and Lee SJ: Treadmill exercise during pregnancy ameliorates post-traumatic stress disorder-induced anxiety-like responses in maternal rats. Mol Med Rep 7: 389-395, 2013.

15. Kohut ML, Boehm GW and Moynihan JA: Prolonged exercise suppresses antigen-specific cytokine response to upper respiratory infection. J Appl Physiol (1985) 90: 678-684, 2001.

16. Pedersen BK and Hoffman-Goetz L: Exercise and the immune system: regulation, integration, and adaptation. Physiol Rev 80: 1055-1081, 2000.

17. Hong JA, Chung SH, Lee JS, Kim SS, Shin HD, Kim H, Jang MH, Lee TH, Lim BV, Kim YP and Kim CJ: Effects of Paeonia radix on 5-hydroxytryptamine synthesis and tryptophan hydroxylase expression in the dorsal raphe of exercised rats. Biol Pharm Bull 26: 166-169, 2003.

18. Lim BV, Jang MH, Shin MC, Kim HB, Kim YJ, Kim YP, Chung JH, Kim H, Shin MS, Kim SS, et al: Caffeine inhibits exercise-induced increase in tryptophan hydroxylase expression in dorsal and median raphe of Sprague-Dawley rats. Neurosci Lett 308: 25-28, 2001.

19. Seo JH, Sung YH, Kim KJ, Shin MS, Lee EK and Kim CJ: Effects of Phellinus linteus administration on serotonin synthesis in the brain and expression of monocarboxylate transporters in the muscle during exhaustive exercise in rats. J Nutr Sci Vitaminol (Tokyo) 57: 95-103, 2011.

20. Lee MK, Lim HH, Song YK, Ko IG, Kim H, Shin MS, Lee TH, Kim CJ, Joo KJ, Park JK and Choi HH: Effects of the mixture of red ginseng and Paeonia radix on the treadmill running and swimming exercise in rats. J Exerc Nutr Biochem 10: 255-263, 2006 (In Korean).

21. Mantovani MS, Bellini MF, Angeli JP, Oliveira RJ, Silva AF and Ribeiro LR: beta-Glucans in promoting health: prevention against mutation and cancer. Mutat Res 658: 154-161, 2008.

22. Rice PJ, Adams EL, Ozment-Skelton T, Gonzalez AJ, Goldman MP, Lockhart BE, Barker LA, Breuel KF, Deponti WK, Kalbfleisch JH, et al: Oral delivery and gastrointestinal absorption of soluble glucans stimulate increased resistance to infectious challenge. J Pharmacol Exp Ther 314: 1079-1086, 2005.

23. Hong F, Yan J, Baran JT, Allendorf DJ, Hansen RD, Ostroff GR, Xing PX, Cheung NK and Ross GD: Mechanism by which orally administered beta-1,3-glucans enhance the tumoricidal activity of antitumor monoclonal antibodies in murine tumor models. J Immunol 173: 797-806, 2004.

24. Neumann-Haefelin T, Wiessner C, Vogel P, Back T and Hossmann KA: Differential expression of the immediate early genes c-fos, c-jun, junB, and NGFI-B in the rat brain following transient forebrain ischemia. J Cereb Blood Flow Metab 14: 206-216, 1994.

25. Hiroi N, Brown JR, Haile CN, Ye H, Greenberg ME and Nestler EJ: FosB mutant mice: loss of chronic cocaine induction of Fos-related proteins and heightened sensitivity to cocaine's psychomotor and rewarding effects. Proc Natl Acad Sci USA 94: 10397-10402, 1997.

26. Dragunow M and Faull R: The use of c-Fos as a metabolic marker in neuronal pathway tracing. J Neurosci Methods 29: 261-265, 1989.

27. Ko IG, Kim SE, Kim CJ, Jung JH, Lee SJ, Kim DH, Lee KY and Kim KH: Effect of treadmill exercise on leak-point pressure and neuronal activation in brain of rats with stress urinary incontinence. Int Neurourol J 14: 141-148, 2010.

28. Hoene M, Franken H, Fritsche L, Lehmann R, Pohl AK, Häring HU, Zell A, Schleicher ED and Weigert C: Activation of the mitogen-activated protein kinase (MAPK) signalling pathway in the liver of mice is related to plasma glucose levels after acute exercise. Diabetologia 53: 1131-1141, 2010. 
29. Han SB, Lee CW, Jeon YJ, Hong ND, Yoo ID, Yang KH and Kim HM: The inhibitory effect of polysaccharides isolated from Phellinus linteus on tumor growth and metastasis. Immunopharmacology 41: 157-164, 1999.

30. Song YS, Kim SH, Sa JH, Jin C, Lim CJ and Park EH: Anti-angiogenic, antioxidant and xanthine oxidase inhibition activities of the mushroom Phellinus linteus. J Ethnopharmacol 88: 113-116, 2003.

31. Kim SH, Song YS, Kim SK, Kim BC, Lim CJ and Park EH: Anti-inflammatory and related pharmacological activities of the $\mathrm{n}-\mathrm{BuOH}$ subfraction of mushroom Phellinus linteus. J Ethnopharmacol 93: 141-146, 2004.

32. Zaidman BZ, Yassin M, Mahajna J and Wasser SP: Medicinal mushroom modulators of molecular targets as cancer therapeutics. Appl Microbiol Biotechnol 67: 453-468, 2005.
33. Majtan J: Pleuran ( $\beta$-glucan from Pleurotus ostreatus): an effective nutritional supplement against upper respiratory tract infections? Med Sport Sci 59: 57-61, 2012.

34. Carpenter KC, Breslin WL, Davidson T, Adams A and McFarlin BK: Baker's yeast $\beta$-glucan supplementation increases monocytes and cytokines post-exercise: implications for infection risk? Br J Nutr 109: 478-486, 2013.

35. Xu C, Lv J, Lo YM, Cui SW, Hu X and Fan M: Effects of oat $\beta$-glucan on endurance exercise and its anti-fatigue properties in trained rats. Carbohydr Polym 92: 1159-1165, 2013. 